NEWS OF THE INTERNATIONAL PALEOSCIENCE COMMUNITY A CORE PROJECT OF THE INTERNATIONAL GEOSPHERE-BIOSPHERE PROGRAMME IGBP
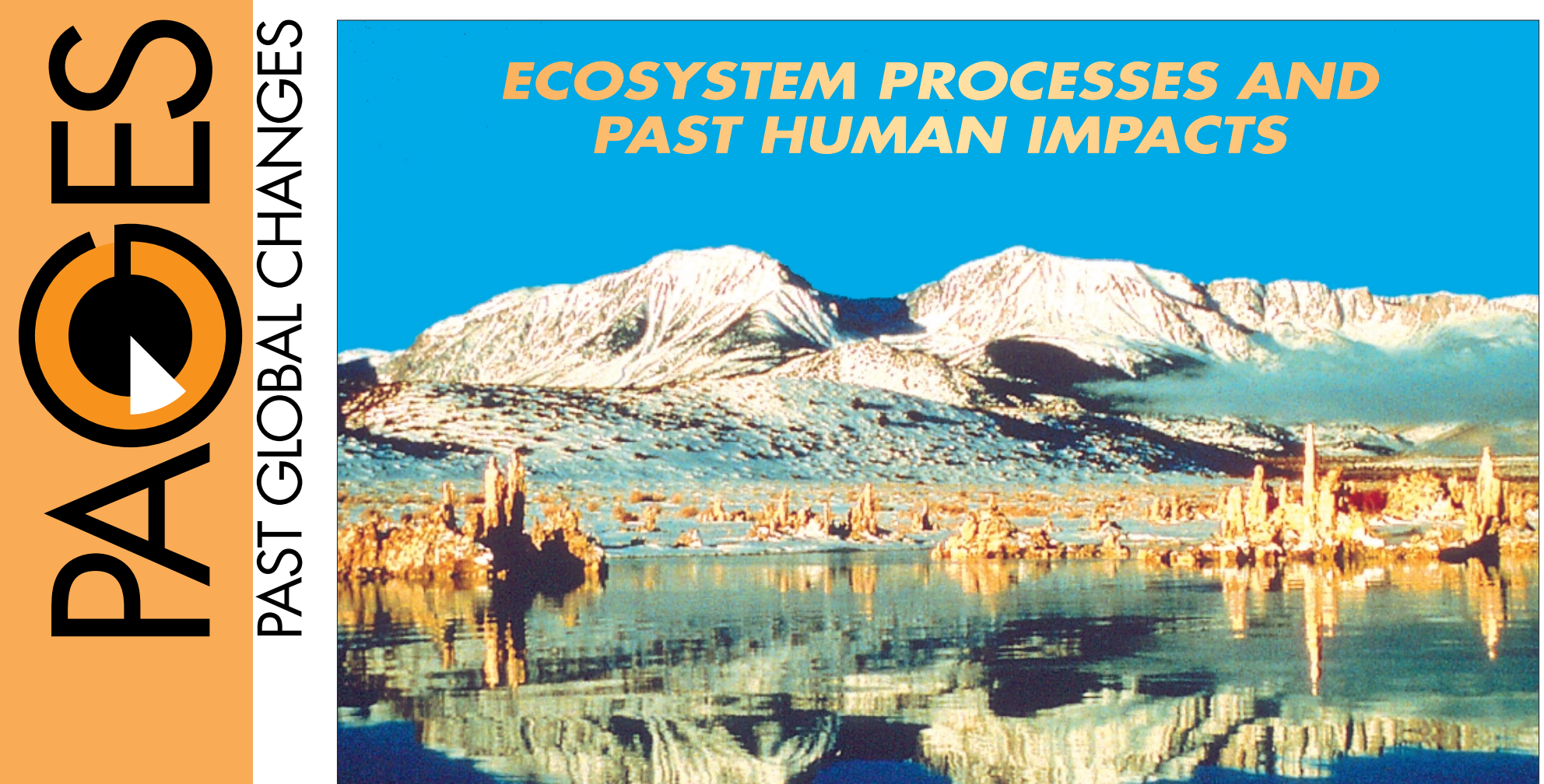

Mono Lake, California. The hydrological systems of the western Great Basin, including relicts of Pleistocene great lakes, are key ecosystems in the semi-arid regions of western United States. Dams and diversions have diverted water to metropolitan and agricultural areas for over 70 years, with significant impacts to endemic species, critical habitats, and human health. The emerged tufa towers surrounding the lake are impressive monuments to the impact of water diversion for human use as this comes to over-ride the effects of natural variability (see article by Constance Millar in this issue).

\title{
EDITORIAL
}

As a result of human actions and their impact on the environment, we now live in a 'no-analogue' biosphere; but these human actions have a history which, in some areas, stretches back over thousands of years. Understanding present day and effectively anticipating future global changes calls for a thorough appraisal of this history, as several of the articles published here emphasize.

PAGES has paid little attention to this theme until recently and this is our first Newsletter to concentrate almost entirely on Human Interactions in Past Environmental Changes, the subject of 'Focus 3' in the PAGES Agenda. Our hope is that this will soon evolve into the broader theme of Past Ecosystem Processes and Human-Environment Interactions - a re-definition that recognizes the need to:

- integrate past human-environment interactions at sub-continental scale with research and modeling based on present day ecosystems and watersheds.

- expand PAGES concern with ecological responses to global change

\section{Ecosystem Processes and Past Human Impacts Editorial}

2 Past Variability and Future Management

4 Past Human Impacts The Human Factor in Paleoclimate, The Ystad Project

8 Historical Ecology Bridging the Biophysical-Cultural Divide

10 Program News Non-Linear Responses and Surprises

10 LUCIFS Russian Plain, Rhine, Lac d'Annecy, Murrumbidgee River, New Zealand

20 LIMPACS

21 HITE Ecosystem Processes and Human Dimensions, LTER, Long Time Series of Ecological Data and Modelling, Vegetation Change in Southern Scandinavia, Long Term Land-Cover Changes in Southern Sweden

Workshop Reports BIOME 300, ELDP

Last Page Calendar, Global Change Open Science Conference 
Editorial, continued from front page

The challenge is enormous and meeting it will be a long-term endeavor. It will involve uniting methodologies from many areas of the environmental sciences, as well as creating true synergy between the perspectives on either side of the biophysical/socio-cultural divide. We have to take into consideration the fact that the diverse cultural basis of all human activities has led to impacts on the biosphere and on biodiversity through time that are strongly differentiated from place to place. We therefore need a regional/case-study based approach designed to improve our understanding of the processes of past global change in all their different manifestations. The present selection of articles illustrates the vigor and diversity of the field, as we begin to include it in PAGES. The contributions include information on the three interlocking strands of 'Focus 3', HITE (Human Impacts on Terrestrial Ecosystems ), LUCIFS (Land Use and Climate Impacts on Fluvial Systems) and LIMPACS (Human Impact on Lake Ecosystems and the role of Paleolimnology), as well as articles with a strongly conceptual and methodological basis and a wide range of case studies including some which illustrate fruitful paleodatamodel interaction in this field.
Out of this vigor and diversity, the challenge will be to develop the best possible unified frameworks for achieving effective research coordination, data assimilation, data-model comparisons, mutually reinforcing interactions between the 'paleo' and 'contemporary' modes of study, as well as regional-global spin-offs in both directions. Bearing in mind that natural resources in general, and food and water in particular, will become integral topics in future global change research programs, PAGES has a responsibility to analyse the dynamic interactions between past natural variability and human activities in the context of a growing world population and its rapidly increasing use of natural resources. We are not discouraged by the enormity of the challenge, for our personal perspective on the recent history of paleo-research convinces us that it is just a question of time, motivation and the urge to cross boundaries and collaborate. We see this newsletter as an early step.

\section{Frank Oldfield}

PAGES IPO, Bern, Switzerland

oldfield@pages.unibe.ch

\section{Bruno Messerli}

Geographical Institute, University of Bern, Switzerland messerli@giub.unibe.ch

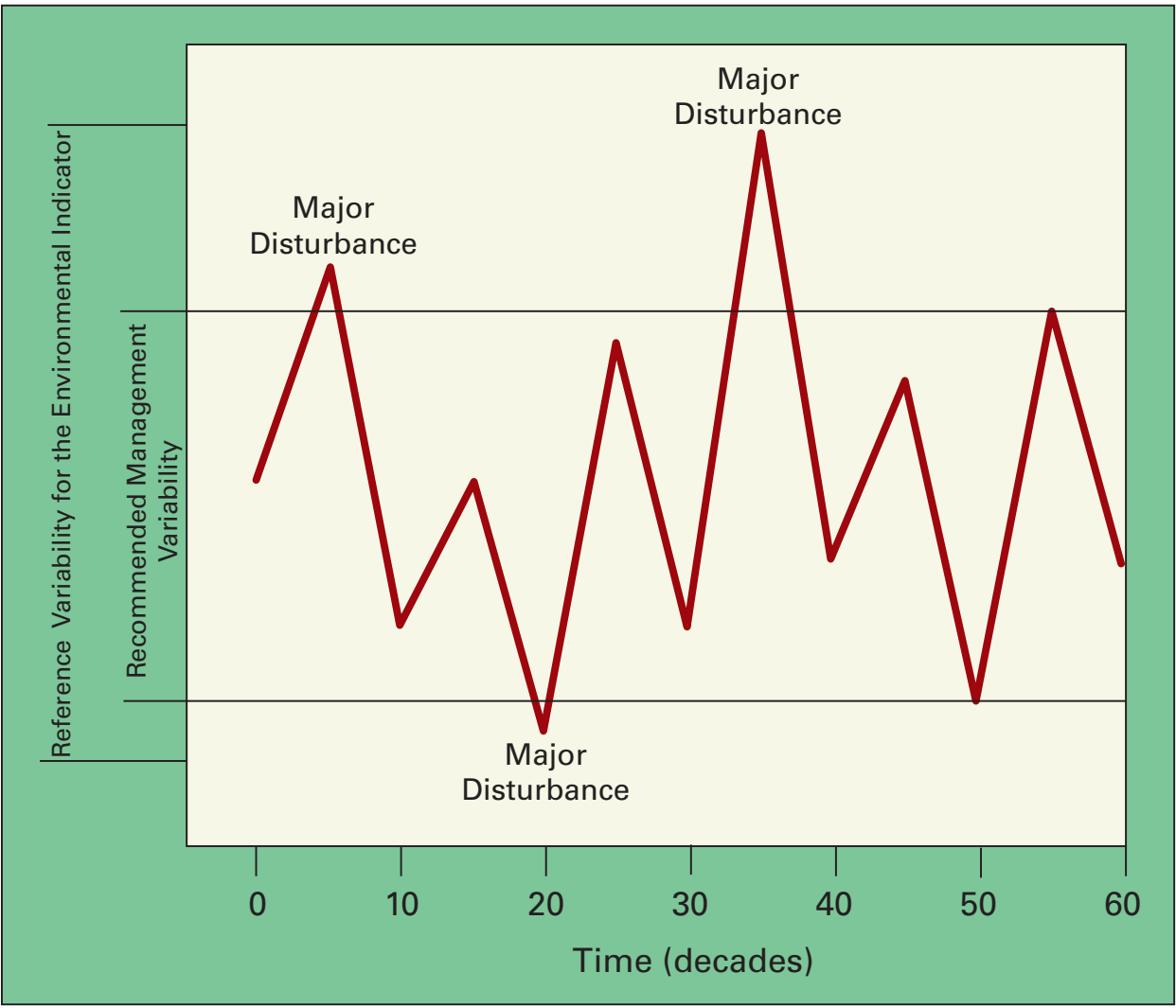

\section{Historical Variability in Ecosystem Management}

As frontiers closed in North America's wildlands during the late $20^{\text {th }}$ Century, ecosystem management emerged as the guiding principle for many public landmanaging agencies. Mandates shifted from emphasis on resource extraction (timber, water, minerals) to ecosystem protection, and the concept of ecological sustainability became central. The mission statements of the U.S. Forest Service, Bureau of Land Management, U.S. Fish and Wildlife Serivce, and U.S. National Park Service, for example, herald ecosystem sustainability - maintaining composition, structure, and process of a system - as key policy goals. Similarly, many conservation programs and non-governmental organizations such as The Nature Conservancy and The Wilderness Society embrace sustainability as a scientific foundation to conservation planning.

Although ecosystem sustainability caught on quickly as a policy goal, implementing it on-the-ground has proven difficult. The newly proposed land management planning rules of the US Forest Service (USDA FS, 1999) are among the first to prescribe operational steps to achieve ecosystem sustainability. The rules, based on a national committee of scientists' report (COS, 1999), codify what has become common thinking among conservation communities: "Ecosystems whose current range of variability, through space and time, approximates the historical range are considered to have high integrity and be in a sustainable condition" (USDA FS, 1999).

Historical variability has thus emerged as a surrogate for sustainable ecosystems. The logic behind this derives from recognizing that ecosystems were functioning adaptably (i.e., sustaining themselves) prior to arrival of modern humans. Thus, if managers

Figure 1: Hypothetical variability of an environmental indicator over 600 years, used as an example of historical, or reference, variability in a federal ecosystem-management guidebook. Such portrayals erroneously assume that background conditions remain unchanging (i.e., have a flat average) over time and that ecological dynamics are contained within a constant range of variation. (USDA FS 1995) 